\title{
POR UMA VONTADE DE DESDIGITALIZAR
}

\section{SUPPORTING A DESIRE OF UNDIGITALIZE}

\author{
Francisco Vieira da Silva \\ Doutor em Linguística pela Universidade Federal de Paraíba \\ Professor da Universidade do Estado do Rio Grande do Norte \\ E-mail: franciscovieirariacho@hotmail.com
}

\begin{abstract}
Claudemir Sousa
Doutorando em Linguística e Língua Portuguesa pela Universidade Estadual Paulista Júlio de Mesquita Filho E-mail: claudemir201089@hotmail.com
\end{abstract}

\section{RESUMO}

Neste artigo, pretendemos analisar como o discurso de desintoxicação digital, presente em uma reportagem intitulada Tchimbum (ed. 2413), da Revista Veja, de 18 de fevereiro de 2015, insere-se no interior das preocupações biopolíticas e constrói uma subjetividade de doente e dependente para o sujeito hiperconectado. De um modo mais específico, pretendemos investigar a objetivação desse sujeito a partir de diferentes saberes que a citada reportagem deixa entrever e os modos de subjetivação propostos para resistir à dependência da tecnologia. Ancoramo-nos teoricamente na Análise de Discurso, mobilizando como categorias analíticas noções-conceitos foucaultianas de enunciado, sujeito, biopoder, biopolítica e cuidado de si. Metodologicamente, nossa análise apresenta uma abordagem qualitativa, de cunho descritivo-interpretativo, partindo da arquegenealogia foucaultiana, que possibilita analisar o feixe de relações de saber e poder que permeiam os discursos. A partir das análises, foi possível concluir que as discursividades sobre o digital na mídia sustentam-se, principalmente, em saberes clínicos, e fazem funcionar mecanismos de feições biopolíticas na medida em que aferem a necessidade de conservar uma vida saudável e feliz, objetivos estes que podem ser prejudicados frente aos ardis das tecnologias digitais.

Palavras-chave: Discurso. Desintoxicação digital. Sujeito hiperconectado.

\section{ABSTRACT}

Abstract: This article aims to analyze how the discourse of digital detox, present in a report entitled Tchimbum (ed. 2413), of Veja Magazine of February 18, 2015, is part of the inside of biopolitics concerns and build a sick and dependent subjectivity for the hyper connected subject. In a specific way, we intend to investigate the objectification of this subject from different knowledge that the 
mentioned report hints at and modes of subjectivity proposed to resist of dependence on technology. The theoretically is based on discourse analysis, mobilizing as analytical categories in Foucault's concepts, notions of utterance, subject, bio-power, biopolitics and self-caring. Methodologically, our analysis provides a qualitative approach, descriptive and interpretative, based on the Foucault's archeology-genealogy, which allows analyzing the beam of knowledge and powerful relations that permeate the discourse. From the analysis, it was concluded that the discourses on digital media supports in knowledge, mainly clinical, and make move mechanisms of biopolitics features, in that counts the need to maintain a healthy and happy life, whose goal out damaged front of the mantraps of digital technologies.

Keywords: Speech. Digital detox. Hyper connected subject.

\author{
Y la obsésion \\ Desencripta lo críptico \\ Viola lo mágico \\ Vence a la máquina \\ $Y$ tarde o temprano \\ Nada es secreto \\ Em los vericuetos \\ De la informática
}

(Jorge Drexler)

\title{
1 INTRODUÇÃO
}

Na edição 2413, da Revista Veja, de 18 de fevereiro de 2015, somos surpreendidos com uma capa, cujos dizeres delineiam uma dada vontade de verdade (FOUCAULT, 2007), ainda que seja por meio de determinada denegação. Tem-se - na materialidade sincrética da capa, diferentemente de números anteriores, prioritariamente centrados em exploração incansável de temas políticos - uma fita amarela com listras pretas, tal como as que são utilizadas para isolar e/ou interditar uma área. Na fita, em caixa alta e na cor preta, constam os seguintes dizeres: Para abrir só depois do carnaval. Em filigrana, sob um tom azul-escuro, aparecem ao fundo excertos da publicação, como notícias e reportagens. No entanto, a ênfase nos dizeres que propõem suspender as informações no decurso do período carnavalesco aguça a curiosidade do leitor. Tal estratégia enunciativa presente na capa delineia modos de ler (CHARTIER, 2002) na relação com o suporte da revista impressa e/ou digital. 
Ao folhearmos essa edição, uma reportagem despertou a nossa atenção, tanto pelas discursividades que fazem circular, quanto pela ligação que se estabelece com os enunciados da capa. A reportagem intitula-se Tchimbum! e fala, em linhas gerais, da necessidade de os sujeitos contemporâneos desligarem-se, ainda que por pouco tempo, dos dispositivos tecnológicos, aproveitando o período carnavalesco como uma oportunidade propícia para um processo denominado pelos autores da reportagem de desintoxicação digital. A nosso ver, seguindo a ordem propugnada na capa, a reportagem em questão só deveria ser lida, após o carnaval, como uma forma de temporariamente, interromper o fluxo contínuo de informações que cotidianamente nos interpela, principalmente se considerarmos que essa reportagem também pode ser lida na versão digital da revista, acentuando, assim, um discurso que sinaliza para uma dependência do sujeito contemporâneo com essas tecnologias, sendo preciso, portanto, delas se livrar,

Nesse sentido, gostaríamos de tomar essa reportagem como objeto de análise neste texto. Visamos, a partir de tal análise, perscrutar o funcionamento de um discurso que proclama a necessidade de adotar uma postura de distanciamento no tocante a uma primazia, muitas vezes exacerbada, das tecnologias digitais na constituição ou, em termos foucaultianos, na fabricação de determinadas formas de subjetividade, nas intermitências dos mecanismos de saber-poder (FOUCAULT, 1998). Para tanto, no encalço das elucubrações de Foucault (2008), entendemos que o enunciado, unidade nuclear do discurso, irrompe, a partir de condições de possibilidade. Noutros termos, é a preponderância do digital na sociedade atual que constitui a pedra angular a partir da qual emergem as mais variadas discursividades, inclusive as que apontam para os perigos advindos do digital, conforme evidenciamos num estudo anterior (SILVA; BARBOSA, 2014).

Considerando ainda que o enunciado funciona numa teia em relação a outros enunciados e discursos, vale salientar que a reportagem a ser analisada aproxima-se de outras formulações, cujos sentidos igualmente sinalizam para um quadro de efeitos danosos do digital em diversos setores da sociedade, mais precisamente na vida e na produtividade dos sujeitos. Tais formulações circularam noutros canais midiáticos, de acordo com o que se confirma numa breve busca na web, quais sejam: Viciada em internet, mulher é internada em SP (TECMUNDO, 01/01/14); Fora do convívio social, viciados em internet podem ter tratamento de usuários de drogas (R7, 06/04/2015); Geração hiperconectada: vício em internet preocupa pais e especialistas (O GLOBO, 16/10/12); Viciados em celular: quem são e como vivem as pessoas que não largam o telefone (UOL, 11/09/12); Por que é tão difícil sair da internet e ir trabalhar, estudar/ler um livro? (SUPERINTERESSANTE, 06/07/11). Registre-se, portanto, para os sentidos de alerta que provêm da materialidade significante desses títulos, no que se refere aos efeitos do uso desenfreado dos artefatos digitais atualmente disponíveis na constituição de sujeitos 
aparentemente doentes e dependentes. Além disso, se pensarmos, mediante a arquegenealogia foucaultiana, que o discurso consubstancia-se a partir de um feixe de relações de saber e poder, é possível adiantar que as discursividades sobre o digital na mídia sustentam-se em saberes, principalmente clínicos, e fazem funcionar mecanismos de feições biopolíticas, na medida em que aferem a necessidade de conservar uma vida saudável e feliz, objetivos que podem ser prejudicados frente aos ardis das tecnologias digitais. Parodiando os poetas árcades, diríamos: fugere digitale!

Assim, no tópico que segue, apresentaremos algumas discussões sobre a análise arquegenealógica foucaultiana para compreendermos: que instâncias promovem a emergência desse discurso nesse momento específico de nossa história; como o uso exacerbado de tecnologias digitais insere-se no interior das preocupações biopolíticas, apontando para os perigos de tais ferramentas; e como o discurso de desintoxicação digital constrói uma subjetividade de doente e dependente para o sujeito hiperconectado. Interessa-nos, assim, investigar a objetivação desse sujeito no discurso clínico que a reportagem citada acima deixa entrever e os modos de subjetivação propostos para o sujeito resistir à dependência da tecnologia.

\section{PERCURSO TEÓRICO}

O campo teórico escolhido para realizarmos este estudo é a Análise de Discurso (AD). Nessa lógica, Fernandes (2007), citando um texto de Pêcheux, aponta três perspectivas de estudos em $\mathrm{AD}$ vigentes na França na década de 80. Uma delas é a que "compartilha com a perspectiva arqueológica foucaultiana a preocupação de considerar as condições históricas de existência dos discursos em sua heterogeneidade" (PÊCHEUX, 1984, p. 56 apud FERNANDES, 2007, p. 47). Essa perspectiva se formou com o entrecruzamento de diferentes áreas do conhecimento, a partir de problematizações sobre a língua, feitas pelos chamados historiadores do discurso como Jean-Jacques Courtine, e influenciou os trabalhos feitos na França e no Brasil atualmente, em que se traçam diálogos entre as investigações de Foucault e a obra de Pêcheux da chamada $3^{\text {a época. }}$

A discussão que empreendemos aqui se ancora nessa vertente de estudos do discurso, fazendo trabalhar no interior da AD algumas noções-conceitos foucaultianas, como a de discurso, enunciado, sujeito e formação discursiva (FD), em torno das quais teceremos algumas considerações.

Foucault (2008a), pela diferenciação em relação a outros elementos, define enunciado como a proposição, a frase e o speech act (ato de linguagem). Para esse autor, o enunciado possui uma singularidade de existência (nem inteiramente linguística, nem exclusivamente material) e 
uma importância fundamental para que se diga se há ou não proposição, frase ou ato de linguagem. O enunciado existe na medida em que existe signo. Assim, "a língua só existe a título de sistema de construção para enunciados possíveis" (FOUCAULT, 2008a, p. 96).

O enunciado não é uma estrutura linguística, “é uma função de existência [...] que cruza um domínio de estruturas e de unidades possíveis e que faz com que apareçam, com conteúdos concretos, no tempo e no espaço" (FOUCAULT, 2008a, p. 98), daí se falar em função enunciativa. É a partir de algumas propriedades dessa função que se vai dizer se uma série de signos será considerada um enunciado ou não.

A primeira delas diz que uma série de signo será considerada enunciado quando, entre ela e "outra coisa", houver uma relação específica que se refira a ela mesma e não ao que lhe deu origem, nem aos elementos que a constituem. Nesse sentido, Courtine (2009) aponta essa propriedade como referencial do enunciado, que forma o lugar, a condição, o campo de emergência, a instância de diferenciação dos indivíduos, objetos, estados de coisa e relação que ele põe em jogo. É ele que dá condições de aparecimento, delimitação e valor de verdade aos elementos linguísticos do discurso. Assim, podemos considerar que o enunciado em análise neste artigo emerge do campo discursivo da clínica.

Outra característica que possibilita-nos delimitar o enunciado é o fato de que ele "se distingue de uma série qualquer de elementos linguísticos porque mantém com um sujeito uma relação determinada, que se deve isolar, sobretudo, das relações com as quais poderia ser confundida e cuja natureza é preciso especificar" (FOUCAULT, 2008a, p. 103-104). É importante destacar que "o sujeito, na perspectiva foucaultiana, não pode ser reduzido a uma entidade linguística nem a uma subjetividade psicológica qualquer" (COURTINE, 2009. p. 86). Esse sujeito não corresponde necessariamente ao sujeito gramatical de primeira pessoa, pois ele não pode ser encontrado no sintagma linguístico. Ainda que não possua primeira pessoa, o enunciado possui um sujeito. Ele é uma função determinada e não coincidente consigo mesmo de um enunciado a outro, na medida em que é uma função vazia, podendo ser assumida por diferentes indivíduos, e um mesmo indivíduo ocupa diferentes posições em uma série de enunciados.

Assim, conclui Foucault, "descrever uma formulação enquanto enunciado não consiste em analisar as relações entre o autor e o que ele disse (quis dizer ou disse sem querer), mas em determinar qual é a posição que pode e deve ocupar todo indivíduo para ser seu sujeito" (FOUCAULT, 2008a, p. 108). No caso em análise, é o sujeito hiperconectado que emerge.

A terceira característica da função enunciativa é o fato de ela só poder ser realizada em um campo associado, constituído de uma trama complexa de enunciados, na qual estão as formulações no interior das quais o enunciado é um elemento. $\mathrm{O}$ conjunto de formulações às quais 
o enunciado se refere, seja repetindo-as, modificando-as, adaptando-as ou se opondo a elas é constituído também pelas formulações a que o enunciado dará origem, que podem via depois dele e pelas formulações:

cujo status é compartilhado pelo enunciado em questão, entre as quais toma lugar sem consideração de ordem linear, com as quais se apagará, ou com as quais, ao contrário, será valorizado, conservado, sacralizado e oferecido como objeto possível, a um discurso futuro [...]. Pode-se dizer, de modo geral, que uma sequência de elementos linguísticos só é enunciado se estiver imersa em um campo enunciativo em que apareça como elemento singular (FOUCAULT, 2008a, p. 111).

Assim, o enunciado nunca está isolado, mas inserido em um campo de outros enunciados, aparecendo com um status que vai possibilitar a ele ser esquecido como enunciado sem relevância ou ser retomado como uma verdade que se sacraliza e abre possibilidades para enunciados futuros. É essa característica que nos permite estabelecer ligação entre a reportagem e os enunciados da capa, bem como analisá-la, inserindo-a numa proximidade com outras formulações que sinalizam para os efeitos danosos do digital em diversos setores da sociedade, mais precisamente na vida e na produtividade dos sujeitos, que circularam noutros canais midiáticos e podem ser encontrados numa breve busca na web, como mostramos acima.

A quarta e última condição para que haja enunciado é que a sequência de elementos linguísticos tenha existência ou espessura material que o constitua. Em suas características intrínsecas, ele possui uma coordenada de espaço e tempo no qual se realiza e também um status. Se essas características mudam, a própria identidade do enunciado muda. Para Foucault (2008a), essas características asseguram que estaremos diante de diferentes enunciações cada vez que um enunciado é repetido em diferentes circunstâncias, pois a enunciação é um acontecimento que não se repete. Porém, o enunciado, apesar de sua materialidade, pode ser repetido. O enunciado possui, assim, uma singularidade e uma repetição. Ele é caracterizado por um regime de materialidade repetível. Essa existência material o distingue da enunciação. “A oposição enunciado/enunciação permite aqui pensar o discurso na unidade e na diversidade, na coerência e na dispersão, na repetição e na variação" (COURTINE, 2009, p. 91).

Pelo exposto acima, o enunciado não é uma unidade linguística, mas sim uma função enunciativa, que permite descrever o discurso como sequências de enunciados, cuja lei de dispersão e repartição é o que Foucault (2008a) chama de formação discursiva (FD). Assim, discurso é um "conjunto de enunciados que se apoia em um mesmo sistema de formação; é assim que poderei falar do discurso clínico, do discurso econômico, do discurso da história natural, do discurso psiquiátrico" (FOUCAULT, 2008a. p. 122). O discurso para Foucault (2008a, p. 123) é prática, ou seja, “um conjunto de regras anônimas, históricas, sempre determinadas no tempo e no espaço, que definiram, em uma dada época e para uma determinada área social, econômica, geográfica ou linguística, as condições de exercício da função enunciativa”. 
A análise de enunciados busca as condições nas quais se realizou o enunciado dentro de um campo de coexistência, ocupando-se de enunciados efetivamente produzidos. Para Foucault (2008a), são os enunciados que demarcam as fronteiras das formações discursivas, entendidas, pois, como conjuntos de enunciados ligados entre si no nível enunciativo. É a FD que define a regularidade do enunciado, sendo, portanto, uma lei de coexistência entre enunciados.

A análise enunciativa proposta por Foucault (2008a) leva em conta um efeito de raridade, que quer determinar porque os enunciados aparecem, e nenhum outro em seu lugar. Estabelecer a lei da raridade desses enunciados compreende o fato de que nem tudo é sempre dito, e os enunciados estão sempre em falta, devendo-se buscar o princípio da rarefação no não preenchimento das formulações possíveis. Isso não significa, alerta Foucault (2008a), que devemos procurar o que foi recalcado ou reprimido sob os enunciados manifestos, não se trata de buscar o que está oculto, mas sim o fato de que poucas coisas podem ser ditas, e se foi dito é, por isso, raro.

Essa análise é caracterizada também pela exterioridade, que restitui aos enunciados sua dispersão, para analisá-lo em sua exterioridade e considerá-los em sua descontinuidade, apreender sua irrupção enquanto acontecimento. Essa exterioridade também supõe que se descrevam as diferentes formas da subjetividade presente no enunciado. “Não importa quem fala', mas o que ele diz não é dito de qualquer lugar. É considerado, necessariamente, no jogo de uma exterioridade" (FOUCAULT, 2008a, p. 139, grifos do autor).

Outra característica da análise enunciativa está nas formas de acúmulo a que ela se dirige, e que Foucault (2008a) distingue de lembranças ou documentos. Os enunciados devem ser analisados nas formas de sua conservação e não em um retorno ao seu passado. Há um grau zero de conservação que é o esquecimento. Por isso, deve-se levar em conta essa remanência dos enunciados, além de sua aditividade a outros enunciados e sua recorrência.

Foucault (2008a, p. 131) aponta quatro direções de análise da formação discursiva, que correspondem aos quatro domínios em que se exerce a função enunciativa: "formação dos objetos, formação das posições subjetivas, formação dos conceitos, formação das escolhas estratégicas". Gostaríamos de falar sobre as duas primeiras, que respondem às condições de emergência dos objetos de discurso e às modalidades de enunciação.

A formação dos objetos diz respeito às regras de aparecimento dos objetos, ao regime de coexistência enquanto objetos de discurso. Para se encontrar essas regras, é preciso primeiramente delimitar as suas superfícies de emergência: onde surgem para depois serem analisadas e diferenciadas. Essas superfícies de emergência irão mudar de acordo com a época, os tipos de 
discurso. É em várias instâncias de diferenciação, nas distâncias, descontinuidades e limiares, que se manifestam, que é definido o domínio daquilo que se fala e lhe atribui status de objeto, tornando-o nomeável e descritivo. Em nossa análise, estamos considerando a Revista Veja como a superfície de emergência do discurso de desintoxicação digital, dentre tantas outras que discursivizam esse objeto.

Depois, devem-se descrever as instâncias de delimitação, que distinguem, designam, nomeiam e instauram objetos. A reportagem deixa entrever o discurso clínico como a instância de delimitação desse discurso de desintoxicação digital, pois a superfície linguística que o nomeia produz um sentido de dependência a ser curada.

Por fim, devemos analisar as grades de especificação que dizem respeito aos modos "segundo os quais separamos, opomos, associamos, reagrupamos, classificamos, derivamos" (FOUCAULT, 2008a, p.47) os diferentes objetos do discurso. Em outras palavras, essa grade de especificação é um sistema de diferenciação de objetos que, aqui, põe em oposição a dependência e o desapego digital.

Quanto às regras da formação das modalidades enunciativas, estas nos permitem encontrar a lei das diversas enunciações e o lugar de onde vêm as formas de enunciados, como se encadeiam, que determinismo há entre uns e outros. Nessa investigação, o primeiro questionamento para se verificar a procedência dos enunciados seria:

\footnotetext{
quem fala? Quem, no conjunto de todos os sujeitos falantes, tem boas razões para ter esta espécie de linguagem? Quem é seu titular? Quem recebe dela sua singularidade, seus encantos, e de quem, em troca, recebe, se não sua garantia, pelo menos a presunção de que é verdadeira? Qual é o status dos indivíduos que têm - e apenas eles - o direito regulamentar ou tradicional, juridicamente definido ou espontaneamente aceito, de proferir semelhante discurso? (FOUCAULT, 2008a, p. 56).
}

Foucault (2008) acredita que seria necessário descrever os lugares institucionais de onde o sujeito obtém o seu discurso, onde se legitima e encontra seu ponto de aplicação. Todos esses lugares se modificam ao longo do tempo. Essas posições do sujeito também são definidas pela situação que ocupa diante de domínios ou grupos de objetos. São situações perceptivas (o sujeito questiona, observa, posiciona-se em relação aos fenômenos que observa), que se somam às que ele pode ocupar na rede de informações. Como já dissemos, é do discurso clínico que Veja recebe o direito de produzir tal discurso. Desse modo, na análise enunciativa, as diversas modalidades enunciativas não remetem à função unificante de um sujeito e sim à sua dispersão, aos diversos status, lugares e posições que ele pode ocupar ao receber ou produzir um discurso, na descontinuidade dos planos de onde fala. 


\section{OS MODOS DE OBJETIVAÇÃO/SUBJETIVAÇÃO DO SUJEITO HIPERCONECTADO PELO BIOPODER}

Em muitos de seus estudos, Foucault (2009) investiga os modos de objetivação/ subjetivação do sujeito. Uma delas é o modo de objetivação naquilo que ele chama de "práticas divisoras", que tentam dividir o sujeito em seu interior e em relação ao outro. A outra diz respeito à maneira pela qual o ser humano se transforma em sujeito. Na esteira dessa discussão, consideramos pertinente mobilizar esse aporte teórico para tratar dos modos de objetivação/ subjetivação do sujeito hiperconectado, que dão a ele um status de doente e propõem modos de resistir ao poder que os artefatos tecnológicos exercem sobre ele.

Segundo Castro (2009), podem-se distinguir dois sentidos para a expressão "modos de subjetivação" em Foucault, pois ele a utiliza para tratar das práticas de constituição do sujeito. O primeiro sentido são os modos de objetivação do sujeito em que ele aparece como objeto de uma relação de conhecimento e de poder; já o segundo possui relação com o sentido foucaultiano de ética e define a maneira como o sujeito se constitui sujeito moral por meio de atividades sobre si mesmo. Nessa via, entendemos que os modos de objetivação e de subjetivação independem um do outro.

Sabemos, com base em Foucault (2009), que as relações de poder estão em contraposição às formas de resistência, pois "lá onde há poder há resistência e, no entanto (ou melhor, por isso mesmo) esta nunca se encontra em posição de exterioridade em relação ao poder" (FOUCAULT, 1999, p. 91). O poder, nessa concepção, está em toda parte, pois é produzido constantemente, em todas as relações. Ele "não é uma instituição e nem uma estrutura, não é uma certa potência de que alguns sejam dotados: é o nome dado a uma certa situação estratégica complexa numa sociedade determinada" (FOUCAULT, 1999, p. 89). Ele não é adquirido, compartilhado e guardado. É exercido em diversos pontos de modo desigual. Por isso, Foucault (1999) considera que existem resistências possíveis e necessárias.

O poder é algo pelo qual se travam lutas. São lutas transversais, pois não se limitam a um país, objetivam os efeitos de poder enquanto tal; são lutas imediatas, porque objetivam o inimigo mais próximo. Para Foucault (2009), essas lutas giram em torno da questão "quem somos nós?" Elas recusam as abstrações que não reconhecem as individualidades e também as cientificidades que determinam quem somos. Daí se falar em modos de objetivação em uma tensão aos modos de subjetivação, pelos quais o sujeito resiste para constituir-se em sujeito de si para si. Ao ser 
discursivizado como um doente, o sujeito hiperconectado deve buscar a resistência ao poder da tecnologia na conversão a si, ou seja, "no próprio sujeito, na relação de si para consigo" (FOUCAULT, 2005a, p. 69), pois há um princípio segundo o qual “é preciso 'ter cuidado consigo"” (FOUCAULT, 2005a, p. 49, grifos do autor), e a tecnologia aparece como uma dependência à qual se deve resistir.

Essas lutas pelo poder se aplicam à vida cotidiana quando se tenta impor uma identidade aos sujeitos, ou seja, quando o poder faz os indivíduos sujeitos de uma identidade. Na atualidade, vemos várias lutas contra a sujeição ou subjetivação. O poder é um modo de ação de uns sobre outros. Ele não é consentido em renuncia à liberdade, pois só se exerce sobre sujeitos livres. Um de seus correlatos é o governo.

$\mathrm{O}$ apego à tecnologia se tornou uma preocupação de governo, demandando uma intervenção política na vida do sujeito hiperconectado, inserindo-se no quadro de questões biopolíticas por meio das quais o Estado promove uma forma de poder que objetiva garantir saúde, segurança e bem-estar à população. Essa preocupação do Estado com a vida da população emerge, segundo Foucault (2009), no século XVIII, quando o homem foi tomado como objeto de poder, que promoveu uma estatização do biológico.

Se na teoria clássica o soberano podia "fazer morrer e deixar viver" (FOUCAULT, 2005b, p. 286) por deter direito sobre a vida e a morte dos súditos, exercendo o direito sobre a vida do lado da morte; na segunda metade do século XVIII, o direito político sofre uma transformação e se instala um novo poder: o de "fazer viver" e de "deixar morrer". Essa nova tecnologia de poder se dirige à vida do homem como ser vivo, enquanto espécie, fazendo aparecer "uma 'biopolítica' da espécie humana". (FOUCAULT, 2005b, p. 289, grifos do autor). Ele se organiza em torno das disciplinas do corpo e das regulações da população e com ele abre-se, diz Foucault (1999, p. 132), "a era do 'bio-poder", fazendo proliferar tecnologias políticas que investem sobre o corpo, a saúde, as maneiras de se alimentar e de morar, as condições de vida, dentre outras.

A biopolítica da espécie humana vai se ocupar "de um conjunto de processos como a proporção dos nascimentos e dos óbitos, a taxa de produção, a fecundidade de uma população etc." (FOUCAULT, 2005b, p. 289-290). Para tanto, será lançado mão da medição estatística desses fenômenos, como forma de produzir um saber sobre os alvos de controle do biopoder. Nesse momento, devem-se tratar as doenças, não porque causam a morte, mas porque subtraem a força e diminuem o tempo de trabalho, causando custos à economia porque necessitam de tratamento. 
Há duas séries de poder: corpo-organismo-disciplina-instituição, de um lado; população-processos, biológicos-mecanismos, regulamentares-Estado do outro. São dois mecanismos que se articulam: um disciplinar, que visa o corpo individual, e outro regulamentar, que se exerce sobre a população. Entre a disciplina e a regulamentação, afirma Foucault (2005b), circula a norma. Por isso, ele fala que vivemos em uma sociedade de Normalização. O biopoder tem por função a normalização da espécie. Ele visa aumentar a vida, controlar acidentes, eventualidades, deficiências e a própria morte, que só aparece em estatísticas. O biopoder vai se esforçar para manter a vida até mesmo daquele que biologicamente já deveria estar morto.

Com a expansão demográfica no século XVIII, em que emerge o problema da população, é a estatística, diz Foucault (2013), que vai revelar as características próprias da população. O objetivo final do governo passa a ser a população, cuja saúde, riqueza e duração da vida devem aumentar. A população passa a ser parte da constituição de um saber de governo e sobre os fenômenos para ela referentes. É assim que se dá, segundo Foucault (2013), a passagem da arte de governar, da soberania, para uma ciência política, dominada pelas técnicas de governo em torno da população do século XVIII. Não se trata da passagem de uma sociedade de soberania para uma disciplinar e depois para uma sociedade de governo, mas de um triângulo em que a população é o alvo principal e os mecanismos essenciais são os dispositivos de segurança. É assim que, desde o século XVIII, vivemos na era da governamentalidade, entendida esta palavra como:

1) o conjunto constituído pelas instituições, procedimentos, análises e reflexões, cálculos e táticas que permitem exercer esta forma bastante específica e complexa de poder, que tem por alvo a população, por forma principal de saber a economia política e por instrumentos técnicos essenciais os dispositivos de segurança. 2) a tendência que em todo Ocidente conduziu incessantemente, durante muito tempo, à preeminência deste tipo de poder, que se pode chamar de governo, sobre todos os outros - soberania, disciplina etc. e levou ao desenvolvimento de uma série de aparelhos específicos de governo e de um conjunto de saberes. 3) o resultado do processo através do qual o Estado de justiça da Idade Média, que se tornou nos séculos XV e XVI Estado administrativo, foi pouco a poço governamentalizado (FOUCAULT, 2013, p. 429).

Governar é uma prática múltipla que pode ser exercida por diversos agentes, entre eles, o pai de família, o pedagogo e o professor. O governo do Estado é uma modalidade entre tantas outras formas de governo, no interior da qual todas as demais estão contidas. A finalidade do governo é dispor as coisas de um modo correto para conduzi-las a um objetivo adequado a cada coisa a governar: fazer com que se produza mais riqueza, com que se forneçam às pessoas os meios suficientes de subsistência, por exemplo. O que se entende por "dispor as coisas", diz o autor, é "utilizar mais táticas do que leis, ou utilizar ao máximo as leis como táticas" (FOUCAULT, 2013, p. 418). Nesse sentido, podemos considerar que a Revista Veja também governa ao propor ao sujeito modos de desapego das tecnologias. 


\section{POR UMA DESINTOXICAÇÃO DIGITAL}

$\mathrm{Na}$ análise a seguir delineada, procuramos aglutinar a teoria, principalmente as reflexões foucaultianas a respeito do discurso, dos saberes, poderes e do sujeito, com o exercício analítico em torno da reportagem de Veja. A partir dos aspectos metodológicos e conceituais da Análise de Discurso, faremos um batimento, na esteira de Pêcheux (2006), entre descrição e interpretação.

A reportagem, intitulada Tchibum! aparece numa seção da revista intitulada Especial. Possivelmente, poderia ter sido uma matéria de capa, caso a publicação não tivesse lançado mão da estratégia enunciativa de que falamos no início deste texto. Nessa medida, considerando a singularidade do enunciado (FOUCAULT, 2008a), a reportagem, no conjunto de todas as coisas ditas, ocupa uma posição de destaque, inclusive em relação aos outros enunciados veiculados no interior da revista. Tal realce coaduna-se com a preocupação que o tema da reportagem suscita na sociedade atual, de modo a propor alternativas para se livrar da relação nociva com todo o aparato digital.

O título da reportagem, portanto, simula o barulho produzido pela imersão de um smartphone na água, ilustrado por uma imagem que ocupa quase duas páginas da revista. Do lado dessa imagem, o lead da reportagem anuncia: "que tal aproveitar o Carnaval para fazer aquilo que, secretamente, você já teve vontade: jogar fora o smartphone e ficar desplugado Mas cuidado, porque a desintoxicação é sofrida." A posição do sujeito que enuncia, nos termos de Foucault (2008a), visa a provocar o sujeito leitor a se desconectar, reconhecendo que este já alimenta um desejo de tomar essa atitude. Em linhas gerais, o saber responsável por esse discurso preconiza o desprendimento, a necessidade de desopilar corpo e mente, de desestressar-se dos compromissos e da correria dos grandes centros urbanos. No convite do sujeito enunciador, essa necessidade encontra respaldo no período carnavalesco, momento de escape prolífico para empreender uma postura de distanciamento das ferramentas digitais ou, numa abordagem foucaultiana, efetuarem certo cuidado de si.

Para mensurar a gravidade do problema, a reportagem lança o seguinte argumento: "médicos consideram que ficar acima de três horas diárias conectado pode transformar um hábito numa rotina prejudicial à saúde" (p.79). Vê-se, assim, a referência a um saber médico (FOUCAULT, 2008b) que outorga o dizer do sujeito enunciador, e, paulatinamente, esquadrinha as práticas do sujeito usuário das tecnologias, descrevendo as frequências e os riscos de uma possível dependência. Além disso, na reportagem são construídos sentidos que nos remetem àquilo que Foucault (2008b) denomina de localização do mal no corpo; noutras palavras, é possível entrever os efeitos nefastos do uso desenfreado das tecnologias na constituição de um 
corpo doente: "checar o e-mail antes de dormir, por exemplo, confunde o cérebro [...] Ficar duas horas consecutivas de frente ao computador resseca os olhos, abre alas para dores de cabeça [...]" (p.80). Esses desconfortos, do ponto de vista do corpo, são constitutivos dessa relação simbiótica do sujeito com os artefatos tecnológicos. Tais problemas embasam a necessidade de dosar o uso dessas tecnologias, conforme apontam, de maneira incisiva, outras passagens da reportagem em análise.

A argumentação por meio do exemplo representa outra estratégia no exercício da função enunciativa da reportagem. Nessa lógica, sujeitos profundamente ligados às tecnologias são instados a darem seus testemunhos, com vistas a demonstrar as formas de vencer a dependência, efetuando a chamada desintoxicação digital. Esses sujeitos, numa fala franca (FOUCAULT, 2001), revelam os efeitos positivos do distanciamento em relação ao digital: "passei a ler e brincar mais com as crianças" (p.80), "não quero me distanciar do que há de prazeroso na vida, como olhar o mundo sem uma tela na frente" (p.81), "a internet nos ajuda a ser produtivos, mas também nos bombardeia com estímulos inúteis que acabam se tornando somente uma fonte contínua de tensão" (p.83). Corroborando essas assertivas, imagens de sujeitos felizes e desplugados plasmam a construção discursiva de certa perfomance vitoriosa, na medida em que tais sujeitos venceram o vício. Num domínio associado, essas posturas assemelham-se a discursividades produzidas por ex-dependentes químicos. ${ }^{1}$

Nesse sentido, as imagens discursivizam sujeitos em poses altivas, jogando celulares e outros dispositivos tecnológicos em sacos de lixo, livrando-se desses de todas as formas possíveis, inclusive destruindo com martelos. As imagens parecem hiperbolizar, em última instância, o triunfo do homem sobre a máquina. Se pensarmos, pois, na perspectiva de Foucault (1998), segundo a qual o saber é um produto de relações de poder, na medida em que o saber e o poder estão diretamente implicados, é imperioso admitir que os saberes que legitimam a aparição desse discurso de desintoxicação digital fazem funcionar um poder exercido sobre os corpos, com vistas a prolongar a vida e referendar uma sensação de bem-estar. Nessa direção, considerando os malefícios advindos do uso descontrolado do digital, esse poder, sob a forma de ações e táticas, atua sobre os corpos dos sujeitos usuários, visando restabelecê-los ao paradigma do conforto e da saúde. Eis a produtividade dos mecanismos do biopoder de que falávamos na seção anterior.

A reportagem acentua ainda algumas representações socialmente construídas em torno do sujeito desconectado. Ao citar um exemplo de três adolescentes que se recusam a utilizar o celular quando estão juntos, a reportagem assevera: "sabem que são como ovelhas negras, mas gostam de se sentir assim” (p.85). Esses sujeitos, conforme defende a posição enunciativa da reportagem, empreendem dada transgressão a uma ordem discursiva vigente: a onipresença do digital. Os 
sujeitos que resistem a esse regime de verdade tendem a ser caracterizados como estranhos e atípicos. Quando se trata de jovens, congenitamente encadeados às tecnologias, as reações de espanto são cada vez maiores; daí a referência a “ovelhas negras".

Os exemplos prodigiosos de sujeitos que conseguiram ter uma relação sadia com as tecnologias são tomados, nos dizeres de Hara (2012), como o consumo de padrões de comportamento e de subjetividades do tipo prêt-à-porter, expostas nas vitrines midiáticas. Noutras palavras, configuram-se como modelos a serem seguidos. Prova disso é o fato de a reportagem citar um livro produzido pela escritora americana Susan Maushart, oriundo de uma experiência realizada pela autora com sua família: ficar desconectados durante seis meses. Com características que parecem lembrar o filão da autoajuda, a obra se constitui num manual de como sobreviver off-line, em tempos de preponderância do digital. Conforme frisa Zielinski (2013, p.81): "Eles [os artefatos digitais] passaram a ser apêndices íntimo das unidades biológicas e as auxiliam a lidar melhor com a realidade instalada tecnologicamente e nela poder interar-se". No intuito de desarticular essa relação com o digital, por vezes insidiosa, o sujeito que enuncia na reportagem mobiliza uma série de vozes e de posições enunciativas.

\section{CONSIDERAÇÕES (IN)CONCLUSIVAS}

As reflexões empreendidas por Foucault fizeram ranger não apenas a história, mas também seu próprio pensamento (DOSSE, 1993), cujos desdobramentos suscitaram toda sorte de contradiscursos, refutações, retomadas e atualizações. A despeito do desaparecimento físico do autor ter ocorrido há pouco mais de trinta anos, a produtividade de suas elucubrações são corroboradas de maneira vigorosa em diferentes campos do saber. As inflexões foucaultianas na consecução da Análise de Discurso francesa possibilitam pensarmos a produção dos discursos na relação com os saberes, poderes e a construção dos sujeitos. Partindo desses pressupostos teóricos visamos, neste artigo, analisar o funcionamento de um discurso que assinala a necessidade de um distanciamento das tecnologias digitais, dada a utilização desmesurada desses artefatos por parte de alguns usuários. Destarte, elegemos como materialidade de análise uma reportagem publicada na Revista Veja (ed. 2413), interessada justamente em discutir essa questão.

Ao analisar o corpus, a partir das teorizações de Foucault, foi possível identificar, na materialidade significante da reportagem, a ebulição de vozes e imagens, cujos sentidos sinalizam para os perigos advindos do uso das tecnologias digitais e as formas de se livrar de certa dependência do digital, atualmente discursivizada em várias vitrines da mídia. Logo, na medida em que aponta os malefícios de usos inadequados da tecnologia eletrônica, o sujeito enunciador da reportagem delineia práticas exitosas de sujeitos que conseguiram a proeza de desconectar-se. 
Nesse ínterim, vislumbram-se modos de fabricação dos sujeitos contemporâneos, emoldurados, conforme nos lembra Foucault (1998), a partir de uma indissolúvel rede de saber e poder. Noutros termos, as técnicas que produzem sujeitos proativos, felizes e preocupados com o bem-estar supõem a nulidade de toda sorte de comportamentos danosos à consecução dessas técnicas. Assim, a reportagem metonicamente dá a ver a multiplicidade do funcionamento desse dispositivo de poder, de acordo com o que demonstramos ao longo do exercício analítico. Sem deixar de sinalizar para as contradições inerentes ao deslindar dessas práticas, convém reconhecer que desdigitalizar parece ser a nova moda no império do digital.

\section{NOTA}

${ }^{1}$ A esse respeito, cf. Silva e Silveira (2015).

\section{REFERÊNCIAS}

CASTRO, Edgardo. Dicionário de Foucault: um percurso pelos seus temas, conceitos e autores. Trad. Ingrid Müller Xavier. Belo Horizonte: Autêntica, 2009.

CHARTIER, R. Os desafios da escrita. São Paulo: Editora UNESP, 2002.

COURTINE, J.J. Análise do Discurso Político: o discurso comunista endereçado aos cristãos. São Carlos: EdUFSCar, 2009.

DREXLER, J. La infidelidad de la era informática. Disponível em: http://letras.mus.br/ jorge-drexler/797718/. Acesso em: maio 2015.

DOSSE, F. História do Estruturalismo, v.1: o campo do signo 1945-1966. Trad. Álvaro Cabral. São Paulo: Ensaio; Campinas: Editora da Universidade Estadual de Campinas, 1993.

FERNANDES, C. A. A noção de enunciado em Foucault e sua atualidade em Análise do Discurso In FERnANDES, C. A.; SANTOS, J. B. C. (Orgs.). Percursos da Análise do Discurso no Brasil. São Carlos: Editora Claraluz, 2007.

FOUCAULT, M. Vigiar e punir: nascimento da prisão. Trad. Raquel Ramalhete. Petrópolis: Vozes, 1998.

História da sexualidade 1: a vontade de saber. Tradução de Maria Thereza da Costa Albuquerque e J. A. Guilhon Albuquerque. Rio de Janeiro: Edições Graal, 1999.

. Os anormais: curso no Collège de France (1974-1975). Trad. Eduardo Brandão. São Paulo: Martins Fontes, 2001.

. História da sexualidade 3: o cuidado de si. Tradução de Maria Thereza da Costa Albuquerque. Rio de Janeiro: Edições Gaal, 2005a.

. Aula de 17 de março de 1976. In: Em defesa da sociedade: cursos no Collège de France (1975/1976). São Paulo: Martins Fontes, 2005 b. 
A ordem do Discurso. Trad. Laura Fraga de Almeida Sampaio. 15a edição. São Paulo: Edições Loyola, 2007.

. A arqueologia do saber. Rio de Janeiro: Forense Universitária, 2008a. $2008 b$.

O nascimento da clínica. Trad. Roberto Machado. Rio de Janeiro: Forense Universitária,

O sujeito e o poder. In: DREYFUS, H. L.; RABINOW, P. Michel Foucault: uma trajetória filosófica para além do estruturalismo e da hermenêutica. Rio de Janeiro: Forense Universitária, 2009.

Governamentalidade. In: MACHADO, Roberto (org.). Microfísica do Poder. 26. ed. São Paulo: Graal, 2013.

HARA, T. Ensaios sobre a singularidade. São Paulo: Intermeios; Londrina: Kan Editora, 2012.

O GLOBO. Geração hiperconectada: vício em internet preocupa pais e especialistas. Disponível em: http://oglobo.globo.com/economia/geracao-hiperconectada-vicio-em-internet-procupa-paisespecialistas-6423247. Acesso em: maio 2015.

PÊCHEUX, M. Discurso: estrutura ou acontecimento. $4^{\mathrm{a}}$ ed. Trad. Eni Pulcinelli Orlandi. Campinas: Pontes, 2006.

R7. Fora do convívio social: viciados em internet podem ter tratamento de usuários de drogas. Disponível em: http://noticias.r7.com/domingo-espetacular/videos/fora-do-convivio-social- vicia dos-em-internet-podem-ter-tratamento-de-usuarios-de-drogas-06042015. Acesso em: maio 2015.

SILVA, F. V.; BARBOSA, M. S. F. O perigo mora na tela: discursividades sobre o digital na mídia. Calidoscópio, São Leopoldo, v. 12, n. 3, set./dez. 2014. Disponível em: http://revistas. unisinos.br/index.php/calidoscopio/article/view/cld.2014.123.06. Acesso em: janeiro 2015.

.; SILVEIRA, E. L. Entre sintomas e suspeitas: discursos sobre o sujeito viciado em internet na mídia, 2015. (No prelo).

SUPERINTERESSANTE. Por que é tão difícil sair da internet e ir trabalhar, estudar/ler um livro. Disponível em: http://super.abril.com.br/blogs/como-pessoas-funcionam/por-que-e-taodificil-sair-da-internet-e-ir-trabalharestudarler-um-livro/. Acesso em: maio 2015.

TECMUNDO. Viciada em internet, mulher é internada em SP. Disponível em: http://www.tecmundo.com.br/internet/49876-viciada-em-internet-mulher-e-internada-em-sp.htm. Acesso em: abril 2015.

UOL. Viciados em celular: quem são e como vivem as pessoas que não largam o telefone. Disponível em: http://tecnologia.uol.com.br/noticias/redacao/2012/09/11/viciados-em-celularquem- sao-o-que-fazem-como-vivem.htm. Acesso em: maio 2015.

VILICIC, F.; BEER, R. Tchibum!. Veja, ano 48, n. 7. São Paulo: Abril, 2015.

ZIELINSKI, S. Ser offline e existir online, Contemporânea, Salvador, v. 11, jan./abril. Disponível em: http://www.portalseer.ufba.br/index.php/contemporaneaposcom/article/view/ 8491/ 6097. Acesso em: 05. jan. 2015. 